\title{
El imaginario del Holocausto en la memoria social de las dictaduras latinoamericanas
}

JORGE MONTEALEGRE ITURRA

UNIVERSIDAD DE SANTIAGO DE CHILE

ABSTRACT: The reconstruction of everyday life for political prisoners, starting with the cases of violations of Human Rights in Chile and Uruguay, implies resorting to memory -with its plurality, diversity and hesitations- as the major source of understanding that contributes to recreating and reassigning the images evoked. Acknowledging the reality and the memory that reconstruct them as social constructs, including the realizations of common sense, the text warns against the processes of transfer and deformations present in the testimonies, illustrating this phenomenon the presence of the Holocaust imaginary in the testimonies of political prisoners in the Southern Cone of Latin America.

Keywords: everyday, Holocaust, imaginary, Latin America, memory, testimony.

RESUMEN: La reconstrucción de la cotidianidad en la prisión política, a partir de casos de violaciones a los DD.HH. en Chile y Uruguay, supone recurrir a la memoria - con su pluralidad, diversidad y vacilaciones- como la principal fuente de conocimiento que contribuye a recrear y a resignificar los espacios evocados. Entendiendo la realidad y la memoria que la reconstruye como construcciones sociales, que incluyen el conocimiento de sentido común, el texto advierte sobre los procesos de transferencias y deformaciones presentes en los testimonios ilustrando esto con la presencia del imaginario del Holocausto en los testimonios de prisión política del cono sur de América Latina.

Palabras clave: cotidianidad, Holocausto, imaginario, Latinoamérica, memoria, testimonio. 


\section{El imaginario del Holocausto en la memoria social de las dictaduras latinoamericanas}

Los prisioneros y prisioneras de las dictaduras viven una situación común, que deviene normal dentro de la excepcionalidad, que les permite interpretar los nuevos hechos extraordinarios que suceden en ella. Al definir un conjunto de actividades como cotidianas, plantea Norbert Lechner, se están definiendo ciertos criterios de normalidad con los cuales, «percibimos y evaluamos lo anormal, es decir, lo nuevo y lo extraordinario, lo problemático. Tal vez el aspecto más relevante de la vida cotidiana es la producción y reproducción de aquellas certezas básicas sin las cuales no sabríamos discernir las nuevas situaciones ni decidir qué hacer» (Lechner, 1988: 57). En esta nueva normalidad se interrelacionan la cultura política y la familiar o privada en la construcción de una cotidianidad que produce un orden social reconocido por el colectivo: una normalidad en la anomalía. En la reconstrucción de dicha cotidianidad es la memoria -con su pluralidad, diversidad y vacilaciones- la principal fuente de conocimiento que contribuye a recrear y a resignificar el espacio evocado. La cotidianidad evocada es, obviamente, una experiencia social previa; pero que constituyó un presente vivido compartido, que está alojado en las memorias -en lugares, objetos, testimonios- y se puede reconstruir socialmente.

Peter Berger y Thomas Luckmann, en La construcción social de la realidad sostienen que todo el conocimiento -incluyendo el sentido común, el conocimiento más básico compartido en la realidad diaria-, se deriva y es mantenido por las interacciones sociales. Así, los elementos clave para entender la realidad como una construcción social se encuentran en la vida cotidiana, la cual se caracteriza por presentarse como un mundo intersubjetivo, de significados compartidos, un mundo contrastable a través de la experiencia con otros. Es en este sentido, en esa trama de relaciones continuas, que la cotidianidad como experiencia previa también es parte de la realidad (re)construida socialmente y que la memoria se constituye así en un cuerpo de conocimiento que llega a quedar establecido como realidad.

La realidad de la vida cotidiana no se agota en el «aquí y ahora», sino que abarca fenómenos que no están presentes en la realidad inmediata como lo son los hechos de la memoria -las experiencias tipificadas, las acciones institucionalizadas- que son objetivados a través del lenguaje y la formación de campos semánticos. Es decir, grupos de palabras que están relacionadas por su significado, por ejemplo las que pertenecen al campo semántico de prisión política. Al respecto, siguiendo la línea de reflexión de Berger y Luckmann, es clave la referencia a que dentro de los campos semánticos se posibilita «la objetivación, retención y acumulación de la experiencia biográfica e histórica», aclarando que esta acumulación es selectiva, ya que «los campos semánticos determinan 
qué habrá que retener y que habrá que "olvidar" de la experiencia total tanto del individuo como de la sociedad» (Berger y Luckmann, 1991: 58). Podemos entender que hay ciertas palabras pertenecientes al campo semántico o nocional que se pueden abrir o cerrar al recuerdo, que pueden tener un mayor o menor poder de evocación y relato, acudiendo también a la memoria cultural.

\section{Proyecciones y transferencias}

En el proceso de objetivación de la experiencia en el lenguaje; es decir, «su transformación en un objeto de conocimiento accesible en general» (Ibíd.: 90), pueden producirse las deformaciones sobre las cuales advierte Michael Pollak al tratar los procesos de transferencia y proyección en su libro Memoria, olvido, silencio. Las mencionadas experiencias tipificadas están sedimentadas, retenidas como experiencias estereotipadas en el recuerdo. Al abordar los procesos de transferencia y proyección, Pollak se detiene en los acontecimientos «vividos indirectamente» para llamar la atención sobre aquellos acontecimientos «vividos por el grupo o por la colectividad a la cual la persona se siente pertenecer». Son acontecimientos de los cuales «la persona no siempre participó pero que, en el imaginario, tomaron tanto relieve que es casi imposible que ella pueda saber si participó o no» (Pollak, 2006: 34). En esa lógica, es pertinente reivindicar la teoría del marco social de la memoria de Maurice Halbwachs, y aseverar que los individuos se identifican con los acontecimientos públicos importantes para su grupo. Es decir, las personas recordamos situaciones que nunca hemos vivido ni experimentado directamente; pero una noticia, por ejemplo, puede convertirse en un recuerdo propio significativo.

En pos de un anclaje de estos conceptos, recordemos que entre los acontecimientos memorables para los prisioneros están aquellos con participación de helicópteros, por la espectacularidad poco habitual que suscitan. Dos relatos de ex presos del Estadio Nacional y Chacabuco recuerdan distintos helicópteros. Ambos ejemplos ilustran, más que lapsus de la memoria, cómo funciona esta y cómo en su ejercicio se mezclan acontecimientos vividos personalmente con acontecimientos vividos indirectamente. En parte del realto de un ex preso chileno, reflexiona: «Si hubiéramos sabido que los helicópteros que el día 19 de octubre de 1973 [sic] vimos pasar en dirección a Calama eran los de la caravana de la muerte del general Arellano Stark...» (Cozzi, 2001: 89). Sin embargo, es pertinente aclarar que en la fecha mencionada -19 de octubre de 1973- a Chacabuco todavía no habían sido trasladados los presos políticos; es decir, era impo- 
sible que el testimoniante y otros presos vieran esos helicópteros. ${ }^{1}$ El caso de la «caravana de la muerte», absolutamente acreditado, se convirtió en una realidad cercana para quienes vivieron la experiencia de prisión política en el desierto y fueron tratados por oficiales que participaron en dicha caravana. La vista de los helicópteros, entonces, en este caso es parte de un fenómeno de transferencia y proyección.

En el segundo caso, relatando sus días en el Estadio Nacional Enrique Jenkin (2011: 82) recuerda el hostigamiento de los militares durante una formación:

¡Todos a la cancha, formar! Mientras un helicóptero con potentes focos iluminaba el estadio. Espectáculo fantasmagórico, hacía recordar el film Apocalipsis Now, con Marlon Brando, en los momentos que las cuadrillas de helicópteros, en Vietnam, se acercaban amenazadoramente, con música de fondo. Cabalgata de las Valkirias de Wagner... tata ¡TATAN! El ensordecedor aspeo se me grabaría en forma indeleble.

Es significativo en el asunto que estamos tratando, que en el manuscrito de este relato la escena haya sido atribuida a Holocausto. El error fue corregido, pero es interesante conocer el proceso de construcción y de registro de una memoria. El imaginario del Holocausto está presente, aunque haya sido omitido en la revisión y enmienda editorial. El hecho, aseverado por otros testigos, es evidentemente la formación obligada y la vigilancia desde el helicóptero que sobrevolaba el lugar iluminando con sus focos. Imagen memorable. Sin embargo, al ser recordada años después la escena evoca otras situaciones. Es probable que después de haber pasado por la experiencia del campo de prisioneros, una escena cinematográfica con elementos similares - campos de concentración, helicópteros-gatille el recuerdo de la prisión personal, sean esas imágenes anteriores o posteriores a la experiencia personal, documentales o de ficción. Es decir, así como el enfrentamiento con la realidad de la prisión pudo ser evocadora del Holocausto (por sus alambradas, focos, torres de vigilancia u otros estímulos); después de la experiencia son las representaciones del Holocausto, con las imperfecciones de la memoria, las que evocan la realidad vivida en un proceso de transferencias que construye una imagen con elementos de diverso origen. En otras palabras, aplicando una linealidad cronológica al relato, son los helicópteros de Apocalipsis Now -de 1979²- quienes evocan al helicóptero del Estadio Nacional de 1973 y no al revés. Y es la fuerza del imaginario del Holocausto lo que induce a un error al nombrar el filme. Todo esto no resta veracidad al hecho relatado (un helicóptero con potentes focos

1. Según el relato, el autor del testimonio -Adolfo Cozzi- estuvo en el Estadio Nacional hasta el 7 de noviembre de 1973.

2. Apocalipsis now, filme dirigido por Francis Ford Coppola estrenado en 1979. 
iluminaba el estadio) visto por muchos; es el hecho de recordar el recuerdo -que también es real-, el que se modifica, interpreta y encuentra su propia retórica personal de resignificación, como en los sueños en que las imágenes se reordenan alterando cronologías construyendo un discurso propio afectado por las experiencias vividas y también por la memoria cultural que se incorpora a las vivencias personales. Así, el episodio que relata Jenkin -una formación en la pista del Estadio Nacional- en el libro de Ángel Parra se relaciona con otra película: «Somos iguales a esos parias de El puente sobre el río Kwai, avanzando a duras penas. Prisioneros de guerra» (Parra, 2005: 86). En estas construcciones que resignifican las experiencias, es dable pensar que los artificios en la narrativa, en estos casos, pueden estar afectados por la distancia espacio-temporal -exilios mediante- que separa a los testigos y el momento de escritura de los acontecimientos narrados; también, por la interacción entre el modo en que funciona nuestra memoria y el modo en que el testigo elige para relatar sus recuerdos: las personas «modifican sus recuerdos añadiendo, sin darse cuenta, hechos y acontecimientos nuevos, o creando ex novo recuerdos de acontecimientos que en realidad no han vivido nunca pero que consideran parte de su vida pasada» (Mazzoni, 2010: 9). Este modo en que funciona la memoria a nivel individual contribuye al entendimiento de cómo se nutre la memoria social. Esta perspectiva -seguida por Pollak, Burke y otros- se fundamenta en la matriz heredada de Maurice Halbwachs quien ya había subrayado - en los años veinte y treinta del siglo $\mathrm{xx}$ - que la memoria debe ser entendida como un fenómeno construido colectivamente, que sufre cambios constantes y está sometido a fluctuaciones, y que son los grupos sociales quienes construyen los recuerdos: nuestros recuerdos son colectivos y nos son recordados por otros.

Lo interesante, respecto de las proyecciones y transferencias implicadas es que los campos de prisioneros -como Chacabuco, Isla Dawson y otros- eran una experiencia inédita para el pueblo chileno y para el mundo respecto de Chile; y que en la construcción de su relato, especialmente en el exilio, se recurre al lenguaje culturalmente más próximo. En la cultura antifascista su proyección encontraba una relación directa con el imaginario de las atrocidades del nazismo. Así, en el campo semántico del Holocausto, están los hornos crematorios, campos de exterminio y Gestapo; palabras a las que recurren diversos testimonios. Hay proyecciones que derivan en disfemismos y exageraciones, destinadas a un receptor que comparte un mismo código genérico que le permite hacer, entonces, las atribuciones de acuerdo al imaginario compartido.

Si bien la memoria y los testimonios -con sus lugares, artefactos y escritos- son fuentes ineludibles en la investigación histórica, la advertencia sobre las deformaciones posibles es digna de ser considerada; y con ella la aseveración de Burke en el sentido de que «son los individuos los que recuerdan en sentido literal, físico, pero son los grupos sociales los que determinan lo que es "me- 
morable" y cómo será recordado» (Burke, 2006: 66). Así, los recuerdos y sus deformaciones pasan a formar parte de la realidad, entendida esta como una objetividad que es, en último término, una subjetividad validada socialmente. Al punto, se hace necesario recordar también que un texto sobre la realidad, producido en base a la memoria, no es la realidad; tampoco es la memoria: es otra transformación que se produce mediante la escritura y la lectura.

\section{Imaginario del Holocausto}

Así como el recuerdo del pasado está afectado por el presente, la memoria reciente -al intentar verbalizarla o ilustrarla- también resulta, en algunos casos, afectada por recuerdos aún anteriores. Es decir, en las vivencias remotas muchas veces está el repertorio de símbolos que permiten abordar la memoria reciente. Símbolos que están al alcance de la mano y en el mapa mental porque en torno a ciertos acontecimientos memorables hay una producción de discursos organizados -que encuadran la memoria-que se comparten en la cotidianidad, tanto en la escuela y la industria del entretenimiento como en los museos, la vía pública y las obras literarias. Sobre estos trabajos de encuadramiento, Michael Pollak plantea que cuando vemos esos puntos de referencia de una época lejana, «frecuentemente los integramos en nuestros propios sentimientos de filiación $\mathrm{y}$ origen, de modo que ciertos elementos son integrados en un fondo cultural común a toda la humanidad» (Pollak, 2006: 27). Ese conocimiento se instala en un campo común de experiencias que facilita la comunicación al respecto. La referencia puede estereotiparse así como puede ser complejizada. También en el plano simbólico la incorporación de esa imagen familiar puede convertirse en un tropo útil para designar figurativamente otra situación: el hecho memorable deviene metáfora -o sinécdoque o metonimia- que ayuda en la construcción de una relación de semejanza, una correspondencia, con otro hecho que en rigor es distinto pero que recurre a la figura retórica para explicarse mejor.

En este campo, las resonancias del Holocausto plantean un desafío y un imaginario. En la recurrencia a la memoria del Holocausto esta se ha constituido -según Huyssen- en un «poderoso prisma» a través del cual, «extendiendo su alcance más allá de su referencia original», se pueden percibir otros genocidios o situaciones que se consideren análogas; es decir, el imaginario del Holocausto permite construir relaciones de semejanza que ayudan a explicar el mundo al ser utilizado, según Huyssen, «como tropos universal del trauma histórico» (Huyssen, 2002: 16-18).

El acontecimiento Holocausto es aparentemente lejano para la América Latina y los jóvenes de los años setenta, pero cercano culturalmente y presente en los estudios de su pasado reciente. Dicho de otra manera: el Holocausto po- 
dría estar ausente de la memoria traumática de nuestros países, pero presente en la memoria de la recepción de productos de la industria cultural y de la revisión histórica. En efecto, por una parte «el movimiento memorialista y las reflexiones sobre la memoria fueron estimuladas a raíz del debate sobre el exterminio nazi» (Ruiz, 2005: 43), que se ha proyectado como un modelo referente; y, por otra, ha incorporado un imaginario que sugiere analogías y metáforas -pertinentes y no tanto- que ayudan a verbalizar y representar fragmentos de la historia reciente latinoamericana. Para esto último es pertinente considerar la memoria legada por la inmigración europea de la postguerra, que se incorpora al capital cultural latinoamericano: «la presencia directa de emigrados españoles y judíos, huyendo de la saña franquista y nazi respectivamente, despertó un eco profundo en el ámbito cultural latinoamericano» (Riquelme, 2003: 205).

Las memorias de la inmigración, la información histórica y los productos de la industria cultural contribuyen a la construcción de un imaginario del Holocausto $-\mathrm{y}$ de la resistencia antifascista- que se adopta con cierta familiaridad y sentido de pertenencia respecto de ese relato. Por ello, a propósito de las proyecciones, transferencias y deformaciones surgidas de los testimonios, es necesario detenerse sucintamente tanto en la presencia del imaginario del Holocausto en testimonios que se refieren a las experiencias latinoamericanas como en las memorias de sobrevivientes de los campos de concentración nazis en cuanto referentes que iluminan la reflexión sobre el pasado reciente del cono sur de América Latina.

El imaginario del Holocausto es parte del acervo cultural de la militancia democrática latinoamericana, adquirida por diversos medios formativos y de comunicación que constituyen los soportes y canales de la memoria colectiva. Pero también es un imaginario presente en los militares. Uno de los principales ejecutores del golpe en Chile, el General Sergio Arellano Stark, en 1974 ve con preocupación que las acciones de la naciente dictadura evoquen las atrocidades del nazismo y entre ellas las purgas al interior de ese régimen. Le escribe a Pinochet: «No es posible que ya se esté hablando de una Gestapo, con todos los macabros recuerdos que esta palabra trae desde los tiempos de la Alemania nazi, cuando se encerraba a los jefes en una torre de marfil» (González, 2009: 468).

En el imaginario del Holocausto hay un trasfondo dramático, con su iconografía documental y ficticia, ante el cual se contrastan las nuevas experiencias locales -directas o indirectas- con escenas de represión militar masiva, de torturas, quemas de libros, torres de vigilancia, campos de prisioneros cercados de alambradas - como las presenciadas bajo las dictaduras latinoamericanas-, la comparación inmediata con algo conocido es con el imaginario del Holocausto, incluidos -entre algunos oficiales- los temores a una noche de los cuchillos largos. Otras referencias para la comparación -como podría ser el imaginario del stalinismo- no estaban incorporadas a un capital cultural colectivo, masivo, de la 
izquierda. Así, la proyección de la memoria colectiva encuentra una relación más familiar y simbólica con el imaginario de las atrocidades del nazismo.

El conocimiento indirecto del Holocausto permitía verbalizar de alguna manera «lo que no tenía nombre», ya que en su campo semántico están los hornos crematorios, campos de exterminio, Gestapo, colaboración-resistencia y otras expresiones descriptivas. No solo palabras, también las imágenes (prisioneros esqueléticos, alambradas, etc.) están en el repertorio de este imaginario que es utilizado tanto por víctimas como por victimarios.

Lilian Celiberti, uruguaya, relatando su prisión en el cuartel de Infantería N. ${ }^{\circ} 14$ de Paracaidistas, cuenta: «a poco de llegar viene un oficial que parece un nazi por su aspecto físico y su forma de hablar» (Celiberti, 1990: 33). Por su parte, Mauricio Rosencof en Memorias del calabozo recuerda el aspecto de sus compañeros rehenes: «era como el de los habitantes de Treblinka. Flacos; el Pepe $^{3}$ con la nariz afilada y los labios hundidos; vos, ${ }^{4}$ escuálido, amarillento, con el cráneo reducido, perdido dentro de un gorrito de Peñarol» (Fernández, 1992: t. III, 93). De la imagen del Holocausto surgida de labios de los militares da cuenta una carta escrita en prisión por Adolfo Nepo Wasem, también rehén uruguayo. Cuenta una conversación política con el comandante de la unidad militar donde estaba preso: «En medio de una discusión muy "urbana" pero muy violenta, se le escapó: "Sí, en realidad con ustedes tendríamos que haber hecho jabón"».

En el capital cultural de las presas políticas de Punta de Rieles estaba presente la lectura de Al pie del patíbulo, el testimonio de Julius Fucik quien fuera decapitado por el régimen nazi. «En él narra las atrocidades de toda prisión y destaca el espíritu de resistencia de los presos por sus ideas», cuenta Blanca Cobas, destacando con admiración el ejemplo: «solo dispuso para ello de un fragmento de lápiz minúsculo y hojillas de papel de fumar, y en ellas, con letra diminuta, escribió el relato de los suplicios y muertes del día a día de los presos políticos checos» (Taller, 2003: 43). Y la ex prisionera agrega que, como sucedió con ella, Fucik también tuvo ayuda de algún carcelero para sacar de la prisión sus hojillas escritas. La comparación va más allá. Las prisioneras recuerdan que los condenados a morir en la horca hacen -durante unos ejercicios en el patioun homenaje a los obreros del mundo. Había sido un $1 .^{\circ}$ de Mayo, fecha que en Punta de Rieles también conmemoraron «sin perder en lo más mínimo el sentido de las proporciones», según Blanca Cobas. «Así, en ese día tan especial, cuando bajamos al patio de recreo y se nos autorizó la gimnasia, comenzamos a hacer flexiones y movimientos imitando el golpear del martillo y el segar de la hoz, como habían hecho los mártires checos» (Taller, 2003: 44).

3. Se refiere a José Mujica, hoy Presidente de la República Oriental del Uruguay.

4. Se refiere a Eleuterio Fernández Huidobro, ex senador del parlamento uruguayo. 
En Chile, Nubia Becker -quien estuvo detenida en Villa Grimaldi- recuerda: «nos tuvieron hacinadas en barracas copiadas de las barracas de los campos de exterminio Nazi» (Becker, 2005: 55); complementariamente, testimoniando sobre su prisión en la Isla Quiriquina, Antonio Leal lo describe como «un campo de concentración que nada tenía que envidiarle a los campos de concentración instalados por los nazis alemanes en Buchenwald y en otros lugares durante la Segunda Guerra Mundial» (Leal, 1975: 289), y Adolfo Cozzi, transmite su impresión al llegar a Chacabuco: «pude divisar el pueblo amurallado, y distinguí un perímetro rodeado de alambradas y torres de vigilancia, igual a las películas sobre campos de concentración alemanes para judíos» (Cozzi, 2001: 39). Luego de esa primera visión los prisioneros son recibidos por un oficial que-según el testimonio de Ibar Aibar- «sus cabellos eran muy rubios, brillantes. No fue difícil asociar su imagen con los fascistas de la "gestapo" hitleriana» (Aibar, 2002: 184). Por su parte, Miguel Lawner se refiere a la Isla Dawson: un «territorio desconocido hasta entonces para los propios chilenos, adquirió una connotación mundial, solo comparable a la alcanzada por los centros de exterminio nazis...» $y$, en otro sentido, reflexiona: «al igual que en la Alemania de Hitler, muchos chilenos cerraron ojos y oídos, negándose a ver lo que ocurría en su propio vecindario» (Lawner, 2003: 13).

Aristóteles España se recuerda en Dawson haciendo la analogía de su prisión con la de los judíos, al rememorar el siguiente diálogo: «"Esto va para largo -dijo mi amigo El Pelle Urrutia-, mientras tanto, tengo mucha hambre". -Yo también -respondí- y me acordé de las películas sobre prisioneros. De los judíos presos, me acordé» (España, 2008: 183). Tanto Aristóteles España, en Dawson; como Adolfo Cozzi, en Chacabuco, son adolescentes en la prisión y pertenecen a una generación que no tiene recuerdos directos de la Segunda Guerra. Ambos, con memoria cultural, recuerdan películas; es decir, en palabras de Alejandro Baer, «el referente histórico ya no es el acontecimiento, sino su representación, es decir, las fotografías, los documentales y el cine sobre el Holocausto» (Baer, 2006: 132). La referencia y la evocación remiten al conocimiento del Holocausto como símbolo de la opresión y asesinato - por parte de los nazis- de diversos grupos étnicos y políticos en Europa; especialmente de la persecución, encierro, exclusión social y política de personas judías, con la consiguiente negación de sus derechos humanos. El llamado Holocausto o Shoah fue un crimen contra la humanidad llevado a cabo «en base a una categoría biológicoracial cerrada» (Sznajder, 2007: 29). Teóricamente, en otros casos de genocidio las víctimas podían salvarse cambiando de bando, de clase o de ideología; pero en el caso del Holocausto, agrega Mario Sznajder (2007: 29):

El genocidio nazi no dejó ningún margen de maniobra como para lograr algún tipo de escape de él. Ni el judío, ni el gitano, ni ninguna de las otras víctimas del 
Holocausto tuvieron oportunidad alguna de redimirse. El eslavo no dejaba de ser eslavo, no importaba cuanto quisiera colaborar con el nazismo. Eran prisioneros de categorías herméticamente cerradas por la lógica del racismo biológico y de las cuales no había manera de huir. Para el judío víctima del Holocausto y confinado en un campo de exterminio nazi, la única liberación era la muerte. Este hecho hace que el Holocausto sea comparable a otros genocidios, pero de la comparación surge también su excepcionalidad.

La comparación no debe ser mecánica, aun cuando los relatos de las víctimas del nazismo han sido incorporados al imaginario social de la humanidad. Es parte de la memoria del horror. Sin embargo, la excepcionalidad debe ser considerada para evitar que las proyecciones y transferencias resulten deformadoras en un encuadre impertinente de la memoria que se desea rescatar. Son ecos de advertencia, un téngase presente en el imaginario social que cuenta -además de los medios de comunicación masiva, que producen una «reificación del pasado hecha por la industria cultural $\rangle^{5}-$ con los sitios, las marcas y acciones de memoria (intelectuales, emotivas, materiales) que evocan los acontecimientos históricos y reproducen el imaginario asociado en los mismos lugares donde hubo exterminio y de donde resultaron prisioneros y prisioneras sobrevivientes. Algunos de ellos han dejado su testimonio y han iluminado la reflexión sobre el pasado reciente del cono sur de América Latina como un gran referente -un cuerpo de conocimientos- ante el cual surgen lecciones relevantes para enfrentar temas regionales contemporáneos que, a fin de cuentas, son de toda la humanidad.

\section{Memoria de sobrevivientes}

Un imaginario, con sus íconos y palabras, afecta otro imaginario. Viviendo la experiencia del campo de concentración de Buchenwald, Robert Antelme recurre a imaginarios remotos -el estereotipo del esclavo egipcio- para encontrar la forma de verbalizar lo que siente y reflexiona sobre su propia autoimagen de entonces (1999: 257):

Es de noche. Lo único que siento es esta cadena sobre el hombre. Hay una imagen del esclavo a la cual uno está acostumbrado desde la escuela. Hay estatuas, pinturas e historias que la representan. Pero no sabíamos -yo, al menos, no sabía- que podía

5. Expresión utilizada por Enzo Traverso en Seminario Historia y Memoria. Universidad Academia de Humanismo Cristiano, Santiago de Chile, 1 de julio de 2010. En la ocasión, el historiador italiano advierte que el Holocausto «tiende a volverse una especie de religión civil» de la democracia y los DD.HH. 
tomar yo mismo esa forma, ser yo mismo ese esclavo del antiguo Egipto, ese prisionero de los asirios... Cada uno tiene en su cabeza una pose clásica del hombre esclavo. Una vez disueltos la angustia, el terror, sentí esa pose, como mi propio caparazón. Me puse a describirme a mí mismo.

El imaginario del Holocausto, con su excepcionalidad, propone un extremo ante el cual se construyen las analogías. El símil, incluido el simulacro mediático, ayuda a pensar y explicar una realidad que permite las relaciones de semejanza entre cosas diferentes (llegar a la conclusión de que son incomparables ya supone una comparación). Pero la identificación no puede ser total ni la transferencia mecánica. El mundo de la apariencia, que facilita las primeras relaciones de semejanza, puede retardar el enfrentamiento creativo de las nuevas realidades que traen sus propias palabras e imágenes. Las memorias de sobrevivientes que tenemos presentes -entre ellas la Trilogía de Auschwitz de Primo Levi; La especie humana, de Robert Antelme; Un psicólogo en el campo de concentración, de Viktor Frankl; La escritura o la vida, de Jorge Semprún- transmiten las vivencias de la situación extrema y también la reflexión sobre ellas. En ese contexto surgen experiencias comparables, en cuanto las similitudes que proporciona el ser humano en su actuar ante la adversidad; en este caso, la prisión política de cualquier época. La crueldad, la solidaridad, el envilecimiento, la creatividad, el oportunismo, el dolor, la felicidad, la vergüenza, están presentes en las situaciones más extremas y ellas -muchas veces- están ejemplificadas notablemente en estas obras cuya trascendencia las convierte en testimonios orientadores en el análisis de los procesos de resiliencia y reflexión de prisioneras y prisioneros políticos bajo dictaduras latinoamericanas.

Hay conocimiento y reflexión trascendente en la literatura que se origina en la experiencia del exterminio nazi; autores, ensayos y testimonios -herramientas teóricas- que iluminan la reflexión en América Latina, articulándose con la producción de escrituras de la memoria y pensamiento crítico local, teniendo el imaginario del Holocausto y sus lecciones como referencia, sin que ello signifique una apropiación cruzada carente de pertinencia ni haga aceptables proyecciones $\mathrm{y}$ transferencias deformadoras.

\section{Referencias bibliográficas}

Agamben, G. (2002): Lo que queda de Auschwitz, España, Pre-Texto.

Aibar Varas, I. (2002): Sol y cielo abonaron mis sueños infinitos, Santiago de Chile, Emege Comunicaciones.

Antelme, R. (1999): La especie humana, Santiago de Chile, Lom.

ArendT, H. (2007): La condición humana, Buenos Aires, Paidós. 
BAER, A. (2006): Holocausto: recuerdo y representación, Madrid, Losada.

BECKER, N. (2005): «Quienes éramos: una agenda para recordar», en Memorias de ocupación. Violencia sexual contra mujeres detenidas durante la dictadura. Santiago de Chile: Fundación Instituto de la Mujer y Corporación Humanas, pp. 43-50.

Berger, P.; T. LuCKMAnn (1991): La construcción social de la realidad, Buenos Aires, Amorrotu.

Burke, P. (2005): Visto y no visto. El uso de la imagen como documento histórico, Barcelona, Crítica.

- (2006): Formas de la historia cultural, Madrid, Alianza.

Calveiro, P. (2004): Poder y desaparición: los campos de concentración en Argentina, Buenos Aires, Colihue.

Celiberti, L.; L. Garrido (1990): Mi habitación, mi celda, Montevideo, ARCA.

Cozzi, A. (2001): Chacabuco. Pabellón 18, casa 89, Santiago de Chile, Sudamericana.

Cyrulnik, B. (2003): El murmullo de los fantasmas, Barcelona, Gedisa.

Dorfman, A. (1986): «Código político y código literario: el género testimonio en Chile hoy», en JARA, R.; H. VIDAL (eds.): Testimonio y Literatura. Minneapolis, Minnesota, USA: Institute for the Study of Ideologies and Literature, Monographics series of the society for the study of contemporary hispanic and lusophone revolutionary literatures N. 3, 1986, pp. 170-234.

España, A. (2008): «Días en el fin del mundo», en Kunstman, W.; V. Torres (comp.), Cien voces rompen el silencio. Testimonios de ex presos politicos de la dictadura militar en Chile (1973-1990), Santiago de Chile, Agrupación Metropolitana de ex presas y presos políticos; Dirección de Bibliotecas, Archivos y Museos.

Fernández Huidobro, E.; M. Rosencof (1992): Memorias de calabozo, Montevideo, Tupac Amaru Editores.

FrankL, V. (1955): Un psicólogo en el campo de concentración, Buenos Aires, Editorial Plantin.

GonzÁlez, M. (2000): La conjura. Los mil y un días del golpe, Santiago de Chile, Ediciones B.

Groppo, B.; P. Flier (comps.) (2001): La imposibilidad del olvido. Recorridos de la memoria en Argentina, Chile y Uruguay, La Plata, Al Margen.

Halbwachs, M.; M. BAeza; M. MuJica (2004): Los marcos sociales de la memoria, Barcelona, Anthropos.

Huyssen, A. (2002): En busca del futuro perdido: cultura y memoria en tiempos de globalización, México DF, Fondo de Cultura Económica.

JENKIn, E. (2010): ¡Exijo una explicación! Mis secuelas de una dictadura, Isla Negra, Chile, Ambos editores. 
LACAPRA, D. (2007): Historia y memoria después de Auschwitz, Buenos Aires, Prometeo Libros.

LAWner, M. (2003): Isla Dawson, Ritoque, Tres Álamos... La vida a pesar de todo, Santiago de Chile, Lom.

LeAL, A. (1975): Denuncia y Testimonio. Tercera Sesión de la Comisión Investigadora de los Crímenes de la Junta Militar en Chile. Ciudad de México, 18-21 de febrero de 1975. Helsinki, Finlandia: Comisión Internacional de Investigación de los Crímenes de la Junta Militar en Chile, 1975.

LECHNER, N. (1988): Los patios interiores de la democracia. Subjetividad y política. Santiago de Chile, FLACSO.

LeChNer, N.; P. Güell (1998): «Construcción social de las memorias en la transición chilena», Ponencia presentada al taller del Social Science Research Council Memorias colectivas de la represión en el Cono Sur, Montevideo, 15/16 de noviembre 1998.

Lecomte, J. (2003): «El buen uso de la memoria y del olvido», en Manciaux, M. (comp.), La resiliencia: resistir y rehacerse, Barcelona, Gedisa, pp. 202213.

LEVI, P. (2006): Trilogía de Auschwitz (Si esto es un hombre, La tregua, Los hundidos y los salvados). Ediciones originales: Se questo é un uomo (1958), La tregua (1963), I sommersi e i salvati (1989); trad. española de Pilar Gómez Bedate, España, E1 Aleph Editores.

Mazzoni, G. (2010): ¿Se puede creer a un testigo? El testimonio y las trampas de la memoria, Madrid, Editorial Trotta.

Nora, P. (2009): Pierre Nora en Les lieux de mémoire, Santiago de Chile, Lom Ediciones y Trilce.

PARRA, Á. (2005): Manos en la nuca, Madrid, Tabla Rasa.

Pollak, M. (2006): Memoria, olvido, silencio. La producción social de identidades frente a situaciones límite, La Plata, Al Margen.

Ricoeur, P. (1983): Texto, testimonio y narración, Santiago, Andrés Bello.

RiQuelme, H. (ed.) (2003): Asedios a la memoria. La experiencia de psicólogos bajo las dictaduras militares en América del Sur, Santiago de Chile, Ediciones Chile-América Cesoc.

Ruiz Cabello, M. (2005): «Los movimientos de la memoria», en Memorias de ocupación. Violencia sexual contra mujeres detenidas durante la dictadura, Santiago de Chile, Fundación Instituto de la Mujer y Corporación Humanas, pp. 43-50.

SEMPRún, J. (2002): La escritura o la vida, Barcelona, Tusquets.

SzNAJDER, M. (2007): «Del Estado-refugio al Estado-conflicto: el Holocausto y la formación del imaginario colectivo israelí», Revista Mexicana de Ciencias Políticas y Sociales, 44: 25-48. 
Taller de Género y Memoria - Ex Presas Políticas (2001): Memoria para armar - uno, Montevideo, Editorial Senda.

- (2002): Memoria para armar - dos. ¿Quién se portó mal? Montevideo, Editorial Senda.

- (2003): Memoria para armar - tres, Montevideo, Editorial Senda.

Taller Testimonio y Memoria del Colectivo de ex Presas Políticas (2006): Los ovillos de la memoria, Montevideo, Editorial Senda.

Taller Vivencias de Ex Presas Políticas (2002): De la desmemoria al desolvido, Montevideo, Editorial Vivencias.

Todorov, T. (2002): Los Abusos de la memoria, Barcelona, Paidós.

- (2004): Frente al límite, México, Siglo XXI Editores.

Verdugo, P. (1985): Los zarpazos del puma, Santiago, Editorial CESOC.

Vitale, L. (1979): La vida cotidiana en los campos de concentración de Chile, Caracas, Universidad Central de Venezuela.

WAGNer, W.; N. HAYes (2011): El discurso de lo cotidiano y el sentido común. La teoría de las representaciones sociales, Barcelona, Anthropos. 